\title{
ANNUAL REPORT OF THE PRESIDENT, $1956^{1}$
}

\author{
By J. W. B. SISAM
}

According to our Constitution, the President normally holds office for two years after his election. This provides him with the opportunity, at the mid-way point of his term in office, to review briefly the activities of the past year and suggest possible lines of development for the next twelve-month period.

During 1956 a number of committees were busy on Institute affairs, dealing in particular with administrative organization, the implementation of an earlier report on membership qualifications, the accrediting of foreign universities, the revision of the C.I.F. Statement of Forest Policy, the preparation of an Institute Manual, the revision of a D.V.A. correspondence course in forestry, and the preparation of a pamphlet on forestry matters in this country for the use of the Department of Citizenship and Immigration.

The Committee on Accredited Universities, under the chairmanship of Mr. R. G. Ray, presented to the Board of Directors a final report, which recommended the acceptance for active membership in the Institute of those applicants who are bona fide graduates in forestry from 31 non-Canadian universities as listed. This report was approved.

The committee responsible for the preparation of a pamphlet for the use of the Department of Citizenship and Immigration, under the chairmanship of Mr. A. L. Best, has completed its task, and copies of the proposed text are being circulated to sections for their information.

All other committees have presented interim reports to the Board of Directors, and their work will continue during the coming year; for each of these, the sections have been or will be asked to review the work under way and to make constructive comments thereon.

In 1955 a first step was taken towards our oft-declared objective, the services of a full-time Secretary-Treasurer. During the past year Mr. J. D. Coats has been employed jointly by the Institute and the Canadian Forestry Association of Ontario. It has been proposed and agreed to by the Board of Directors that over the next three years an increasing proportion of Mr. Coats' time will be be devoted to Institute affairs and that we will be responsible for an increasing share of his salary with the aim that by $1959 \mathrm{Mr}$. Coats will be employed solely as Secretary-Treasurer of the Institute. This arrangement has now been approved by both organizations.

While the appointment of a full-time secretary need not of itself bring about any marked increase in Institute activity, nevertheless with the right man in office, it should result in a much closer liaison between sections and head office and assist greatly in the implementation and increase the effectiveness of any activity that is undertaken at the national level, particularly an activity or program requiring centralized promotion or servicing.

Turning for a moment to the external affairs of the Institute, probably

\footnotetext{
${ }^{2}$ Report presented to the 48th Annual Meeting of the Canadian Institute of Forestry held
} October 5, 1956 at Chicoutimi, P.Q. 
the most important event of the year-and one that can have even greater significance in the future - was the preparation and presentation of the Brief to the Royal Commission on Canada's Economic Prospects. This statement is significant, not only for what it has to say and the purpose for which it was prepared, but also as an example of what can be accomplished when the need arises.

The text of our Brief to the Royal Commission was prepared on your behalf. It conforms closely, I believe, with the ideas expressed in our Policy Statement, as was explicit in the resolution authorizing its presentation. This brief should provide an excellent point of reference for further discussion and study by members of the Institute. To this end it is most important that every member should read it thoroughly and have some appreciation of its implications.

Another event, which can be of considerable importance to the future development of forestry in this country was the National Forestry Conference held in Winnipeg during the week of September 17th; this conference, for which the Institute had some responsibility and in which many of our members took part, was a natural outcome of the National Resources Conference held in Ottawa in 1953.

While the Winnipeg conference was co-sponsored by the Canadian Forestry Association, the Engineering Institute of Canada, the Canadian Chamber of Commerce, and the Canadian Institute of Forestry, the bulk of the work in its planning, organization, and production, fell largely to the C.F.A., and I should like to take this opportunity on behalf of our Institute to thank that Association and its officers, in particular Mr. Harold Fisk, Mr. James Vance, and Mr. J. L. Van Camp, for the great contribution they have made to forest conservation through the success of this undertaking. Having in mind the 1954 resolution of this Institute with respect to the further implementation of the Canada Forestry Act, and the subsequent action taken by a number of our sections, it was particularly gratifying to hear the Minister of Northern Affairs and National Resources announce at this conference that the Federal Government was prepared to assist in some degree with the costs of forest fire prevention where this was required.

With a few exceptions, the activities of the sections have been at a generally high level during the year, the individual projects varying of course in accordance with local interests and conditions. Over the past few months I have had the opportunity to attend the meetings of five sections, and I would hope that in time it will be possible for the President and/or the Secretary to visit each section at least once every two years, so that a closer personal relationship may be established between the membership and head office.

In reviewing our past activities, the question inevitably arises as to whether we are accomplishing all we should, having in mind our objectives, the interests of our members, our facilities, and the potential effort available in the organization. This question has been emphasized in my mind from discussions and correspondence with individual members as well as the definite but constructive criticism that has been made from time to time in The Forestry Chronicle and elsewhere. 
Certainly there never was a time more opportune than the present for this Institute to make a really worthwhile contribution to our professional development and to the future economy of the country-and that simply by doing everything in our power to implement and promote our main objectives"to encourage wider understanding of the problems of forestry and improve forestry practice in Canada". To many of us these objectives may seem to be of too general a nature. But if we are agreed they are sound, surely it is our function to interpret them and put that interpretation into effect. From a purely selfish viewpoint progress towards these objectives should be of importance to all foresters, as it must in time lead to an improvement in their professional status and opportunities.

The first of these objectives-to encourage a wider or better understanding of the problems of forestry among the Canadian people-was essentially the theme of the National Forestry Conference. Two of the key papers were entitled "Forestry and Canadians" and "The People and Their Forests", and in his introductory address at the Conference Lowell Besley stated that "The basic philosophy of sound forest management must be known to the citizens of Canada, if they are to see to it that the forest areas, which they own, are managed intelligently." It is only a question of informing the people of the values involved and the economic importance of their protection, vital as these are; we must go further if the layman is to have an intelligent understanding of the role that foresters play-and who better can inform the public on these matters than the foresters themselves.

To this end, should not the Institute be making a more concerted and organized effort in public education? Thus far some excellent work has been done by individual sections, but at the national level our efforts, apart from co-sponsoring two national conferences, have been confined to the appointment of committees and the presentation of reports, excellent in themselves, but needing implementation to be effective. Recently I received a letter from an organization having something the same pattern as our own but representing another profession. This letter informed me that that organization was prepared to provide speakers on their subject to interested groups in any of the main centres of this country. Their report on the extent to which this service had been used during the past year was impressive. In the organization and promotion of panels of speakers or any other aspect of public education, including the development of our relations with the press, there can be little doubt that there is much room for improvement. Our having a permanent officer at head office should prove of great value in this connection.

Forest education in its broadest sense is probably the best means, if not the only means in some cases, of the Institute attaining its objectives. To assist in the furthering of our work in this field, the Board of Directors at its recent meeting authorized the setting up of a standing committee to be responsible for developing an Institute policy with respect to forestry education, both professional and public, and to promote and co-ordinate greater activity in this field.

The responsibilities of the Institute for technical advancement in forestry are defined briefly in our Constitution-"To advance the members in their knowledge of the science and practice of forestry and to improve forestry 
practice in Canada." Undoubtedly some progress is being made with the first of these objectives through the presentation of formal papers and the discussions that take place at annual and section meetings, and through the publication of The Forestry Chronicle: means are thus provided for the exchange of ideas and the dissemination of useful information among our members, and in some instances this may lead directly to practical improvement in the field.

Also of importance in this connection have been the Standing Technical Committees, each representing one of the main branches of forestry, whose functions are mainly to report each year on current practices in their respective fields and to suggest problems that require study. Over the years there has been considerable variation in the interest in, and activity of, these committees. This may be understandable, having in mind the changing emphasis on different aspects of forestry from time to time. On the other hand there may be a need to review again our organization for technical development, a suggestion that appears to be borne out by the discussions and correspondence $I$ have had with some of the committee members.

One point to be considered is the size and representation of these committees. While at present their membership is relatively small, it was suggested in last year's report on committee organization that to be effective they should have a large membership and countrywide representation. This suggests that it might be worth our considering the pattern followed by the Society of American Foresters, whereby all members of the Society belong to one or other of its technical divisions, according to their interests. This has the advantage of associating all members with the technical work of the organization, and should stimulate interest in these matters as it has undoubtedly done in the S.A.F. On the other hand there is the danger, particularly in an organization with a relatively small membership, of diverting interest to special fields at the expense of forestry in general. These two aspects are, of course, interdependent. Scientific progress in forestry must often depend first on developments taking place in one or other of the applied sciences on which it is based, but we should not lose sight of our main purpose-the proper integration of the parts, including Silviculture, Protection, Utilization, and so on, to make for the best possible progress in the overall practice of forestry.

One possible means of overcoming, in part at least, the difficulty $\mathbb{I}$ have mentioned would be to establish a technical advisory council consisting of the chairmen of the various committees or subdivisions and the Executive of the Institute to meet at the time of the Annual Meeting. The function of this council would be to review and assist in the overall technical program of the Institute and, so far as possible, to suggest means of co-ordinating the work of the various subdivisions. From this council might well come suggestions for projects that could be undertaken by the Institute after being approved by the Board of Directors.

Both this council and the various technical subdivisions of the Institute might contribute much to the planning and preparation of programs for our annual meetings. The value of this approach has, I believe, been well illustrated this year when the Standing Committee on Wood Utilization assisted the Saguenay Section in developing a technical program for these meetings. 
One further step towards maintaining a proper balance between specialization and general forestry is the suggestion that some time in the future the pattern for annual meetings might require that one half of the time be devoted to matters of general interest, including perhaps a session that would be open to the public, as has been recommended by our Board of Directors, and the second half be a series of overlapping technical sessions, preferably not more than two or three groups taking part in any one year and these with as little in common as possible. Thus over a period of two or three years each technical group or division would have the opportunity of holding a formal session within the regular program of the Annual Meeting. Keeping the number of sessions at two or three a year might have the advantage of a larger attendance and give members a better opportunity to hear what is being done in fields other than their own.

It may be noted that the Board of Directors has agreed that the technical organization of the Institute should be reviewed during the coming year and that a report on this subject be presented at the 1957 Annual Meeting.

In conclusion, may I express my very real appreciation to all officers of the Institute, chairmen and members of committees and many others for the time and effort they have given to our work during the past year. I expect that the demands will be even more pressing during 1957: I trust the response will be as satisfactory. 